\title{
Models for Humanitarian Health Care Ethics
}

\author{
Lisa Schwartz*, Department of Clinical Epidemiology \& Biostatistics, and Centre for \\ Health Economics \& Policy Analysis, McMaster University \\ Matthew Hunt, School of Physical and Occupational Therapy, McGill University \\ Chris Sinding, School of Social Work and Department of Health, Aging \& Society, \\ McMaster University \\ Laurie Elit, Department of Obstetrics and Gynaecology, McMaster University \\ Lynda Redwood-Campbell, Department of Family Medicine, McMaster University \\ Naomi Adelson, Department of Anthropology, York University \\ Sonya de Laat, Department of Clinical Epidemiology and Biostatistics, \\ McMaster University \\ *Corresponding author: Lisa Schwartz, Department of Clinical Epidemiology and Biostatistics, Arnold L. Johnson Chair in Health Care Ethics, \\ Centre for Health Economics and Policy Analysis (CHEPA), McMaster University, 1280 Main Street West, CRL 224, Hamilton, Ontario, Canada L8S 4K1. \\ Tel: +1-905-525-9140 (extn: 22987); Fax: +1-905-546-5211, Email: schwar@mcmaster.ca
}

Humanitarian health care practitioners working outside familiar settings, and without familiar supports, encounter ethical challenges both familiar and distinct. The ethical guidance they rely upon ought to reflect this. Using data from empirical studies, we explore the strengths and weaknesses of two ethical models that could serve as resources for understanding ethical challenges in humanitarian health care: clinical ethics and public health ethics. The qualitative interviews demonstrate the degree to which traditional teaching and values of clinical health ethics seem insufficient for addressing all the realities of health care practice during humanitarian missions. They equally suggest that greater good orientations of public health ethics can thwart the best intentions of health care professionals wanting to attend to the interests of individual patients. Even though neither is complete on its own for helping guide health professionals on field missions, taken together these models have much to offer. At the same time, the narratives of the humanitarian health care workers illustrate how some of the crucial differences between public health ethics and clinical ethics generate tensions in humanitarian health practice. We offer an analysis of some of the complexities this creates for humanitarian health care ethics, and consider ways of adjudicating between the two models.

\section{Introduction}

A recurring ethical theme in humanitarian health care work is whether or to what extent humanitarian health care practice ought to be guided by a greater good orientation. We will examine this question using conceptual analysis, and will illustrate the tensions that emerge related to providing care for individuals when community interests demand attention by using verbatim quotations and drawing upon inductively-developed findings from a qualitative study of humanitarian health care professionals.

In their home settings, in order to help manage ethical responsibilities and difficulties, health care professionals are trained in, and expected to apply, the codes and values of ethics of their professions and those of the institutions in which they provide health care. NGOs and other health-oriented aid agencies expect their volunteers to derive guidance from these same codes and policies. As one prominent medical relief organization put it,

Health professionals are guided by their training and the requirements of their licensing boards for their ethical behaviour. (Personal correspondence)

These codes have long histories, are well considered for their context and professions, and are certainly laudable. However, while there will be some similarities, clinical work in humanitarian health care practice is 
not the same as clinical work in home contexts so preparation in ethics ought to reflect these differences. Among the significant differences, health care practice for expatriates in humanitarian and development work involves relocation to another country to work in contexts where material and health resources are scarcer, needs are greater and population health considerations are prominent. For these expatriate clinicians, the local social and political contexts are often experienced as unclear, there is a lack of familiar supports, accountability and governance may be less certain and roles and responsibilities may be less defined. In some settings, colonial history and political insecurity are important background features. In addition, expatriate clinicians work within structures and mandates of humanitarian NGOs, and this provokes its own set of tensions (Schwartz et al., 2010; Hunt, 2008). It is not entirely surprising then, with such significant contextual differences, that the ethical challenges described by humanitarian health workers are also distinct, raising the question of whether the value ordering and other ethical considerations that help guide this work may be similar and distinct as well.

There do exist statements of humanitarian ethics from various humanitarian organizations such as the International Federation of Red Cross Red Crescent (IFRCRC, 1965), and the Sphere Project. For example, the Fundamental Principles of the IFRCRC describe the commitments of the organization that include humanity, impartiality, neutrality, independence, voluntary service, unity and universality (Pictet, 1985). However, these statements are intended for, and do their best work at the organizational level. At the individual clinical level, the principles can create conflicts between organizational values and on-the-ground clinical requirements, and like so many principle-based statements, no direction is given for how to resolve cases where principles conflict (Hilhorst and Schmiemann, 2002). This is a problem for principlism in general, as it is for any ethical theory that supports more than one value, and requires wider discussion that is outside the scope of this article. These problems are further confounded because no guidance has been given to clarify which ethics statements humanitarian health care professionals ought to favour if, e.g. their professional licensing requirements conflict with organizational statements.

If humanitarian health care professionals were to rely exclusively on the codes and values of their professions and home country institutions, they would be guided by values which pre-suppose a high level of resources and are based primarily upon experiences of clinical care for individual patients. These codes originate from contexts of comparative abundance that permit focus on individual best interests underpinned by emphasis on respect for patient-led decision-making (Charles et al., 1997, Munthe et al., 2011). Unfortunately, the realities of disease outbreaks, limited resources, security issues and disasters (or a combination thereof, as in the aftermath of the 2010 earthquake in Haiti) mean that individual interests cannot always be foremost for humanitarian aid; so Western clinical ethics may be misplaced or insufficient in these contexts.

It is tempting to look to public health as an alternative ethical model ${ }^{1}$ to provide guidance in this context. After all, the kind of work involved is often directly public health-oriented (e.g. vaccination and other disease prevention programs). Public health concerns are often pronounced because of the extreme circumstances, characterized by emergency, large number of effected people, prevalence of poverty, geographic remoteness or high population density (as in refugee camps). In addition, aid organizations sometimes apply public health mandates to their policies and this influences the way practitioners carry out their work, such as policies that focus care on specific conditions to the exclusion of others. Some humanitarian and development projects include public health interventions (e.g. cholera treatment programmes) without actually being classic population health projects - they seem to fall in a zone which cannot be neatly divided between public health interventions on one side, and clinical practice on the other.

The public health ethics model has been described as quite distinct from models of Western clinical ethics. Most significantly, it emphasizes community interests and collective activities.

... we have argued that public health activity involves two key features. First, it should aim at protecting and promoting the health of a large group or population (this excludes individual clinical encounters between doctors and patients). Second, public health actions will involve collective activities by, for example, governments, health care systems, or even society as a whole (this excludes action to improve the health of a particular individual unless it is within the context of a campaign targeted at a group or population). (Dawson and Verweij, 2008)

Hence, there exists a tension. On the one hand, the values and principles invoked in public health practice represent a model of community-oriented interests not focused on individuals except to the extent that to do so coincides with the greater good. As Solomon Benatar $(2006)^{2}$ puts it, 'Public health activities must therefore 
of necessity be directed at enhancing the health of whole populations. This goal may conflict with the desire to always place the rights and needs of individuals above those of society'. On the other hand, clinical ethics, as it is instantiated by the licensing boards of Western health professions, tends to focus on the individual patient, valuing individual best interests and, at least since the twentieth century, invoking the duty to respect patient autonomy (WMA).

These two models of health ethics, public and clinical, could be drawn upon together in theory. However, as the definitions above make clear, the 'greater good', population orientation of public health is, at least some of the time, in direct conflict with the face-to-face clinical care provision in which humanitarian health care practitioners are trained and engaged. The clinical ethics model is a foil to greater good-oriented interventions that would compromise individual interests. The public health ethics model, in contrast, is a foil to extreme individualism, and promotes shared community interests. The two can be harmonized, in theory, but not all the time. In this article, these two models of health ethics for aid workers will be explored as ethical orientations for clinicians in humanitarian health care. Using data from empirical studies, we survey their strengths and weaknesses as models for understanding and responding to ethical challenges in this context. The narratives of health care workers illustrate how sometimes irreconcilable differences between the ethics of public health and the ethics of clinical care become a source of confusion and ethical challenge in humanitarian healthcare practice.

\section{Empirical Research}

In order to better understand the nature of ethics in humanitarian health care provision, we undertook a qualitative study that included in-depth individual interviews with 20 Canadian health care professionals. We asked them about their experience of ethical challenges encountered while providing health care in situations of extreme poverty and scarcity, disaster or armed conflict. We identified four main sources of ethical tension: (i) resource scarcity, (ii) inequalities related to historical, political, social and commercial structures, (iii) aid agency policies and agendas and (iv) perceived norms around health professionals' roles and interactions. We examined the impact these had on the personal and professional identities of the workers (Hunt, 2008). In a related study, the author identified a similar range of origins of ethical challenges in humanitarian and development work: (i) tension between respecting local customs and values, and acting in ways that are consistent with one's core moral convictions, (ii) barriers to the provision of adequate care, (iii) divergent understandings and experiences of health and illness, (iv) questions of identity as a professional, humanitarian and moral person and (v) issues of trust and distrust.

Below, we offer three cases drawn from respondents' stories that show how tensions between clinical and public health ethics emerged and unfolded. Among the cases that were resolved using greater good justifications were cases where health providers were involved in public health projects and single disease-oriented vertical programs set up by aid organizations. In such cases, the respondents were confronted with role challenges illustrative of the clash in models between direct patient care and public health. ${ }^{3}$ In all cases presented here, the respondents felt a lack of ethical guidance to draw upon leaving them uncertain about what was the right thing to do.

\section{Case 1, Individual Needs}

As a nurse based in Africa, one respondent described the experience of not being permitted to treat $\mathrm{TB}$ where a country was at war and before recent evolutions in public health practice in conflict settings that better represent her ethical values as a practitioner.

In [this section of Africa] it was considered unethical to provide $\mathrm{TB}$ treatment because the country was at war... Not unethical but it was medically unwise in a non-safe context to put a lot of people on treatment because if the war would burst and people would have to interrupt their treatment, which is a minimum 6 months, then people are at risk of developing resistant tuberculosis and then spreading it around.

The respondent refers to the decision as '... a very public health issue which has been the case for a long time in countries like Sudan and Angola' because of the long history of war. So at that time, the approach of 'WHO and MSF and many agencies' was to not begin a TB treatment program without the guarantee of sufficient time and access to patients to be able to treat them for long enough to pre-empt the development of drug resistant strains. While she appreciated the public health strategy behind this decision, the respondent was confronted with its tangible consequences.

But when I arrived this was not only about talking about medical issues about treating or not 
treating, it was me I knew those drugs were there. I knew the drugs were available but because of a medical policy decision it was me that had to say to this woman with her kid in agonizing sufferance that, you know, we don't treat this disease so the only thing I can tell you is that you should go and die at home. And all I can give you is food, when I mean the kid could not even swallow anymore. He is a zombie and you know what the problem is $90 \%$ of course but you're not doing it because-you know policy wise and security wise what is the ethics of this? It's not about philosophy, you're the one who is telling to this mother you take your kid home to die.

She describes the weight of having the responsibility of carrying out the decision with a specific person. '... when you're working you've got that one kid in front of you...'

As a nurse and a professional with a code of ethics which affirms the significance of the patient's best interest, she (and those who recounted similar situations) was confronted with an irresolvable challenge to her understanding of the ethical demands of her profession. She appreciates that a greater good-oriented outcome will protect the community from spread of treatment resistant TB. Nevertheless, later she speaks of believing that the agency she went with 'could have done much more'. In addition, she feels a commitment to the value of the single child before her, as well as her professional commitment to attend to the interests of the patient who seeks her help. There is no clear way to resolve the dilemma, though this particular respondent does seem to arrive at the conviction that it was wrong not to treat.

It bears mentioning the irony of this philosophical treatment of the dilemma, in relation to the respondent's clear statement: 'it's not about philosophy'. She seems to suggest there is something else going on here: that the actual embodied telling of this mother to take her child home to die, is outside the realm of detached analytic treatment and fails to tell the full story. ${ }^{4}$

\section{Case 2, Greater Good}

In the following case, a nurse working in Africa encountered a cholera outbreak that created a role dilemma. Assigned to the hospital to provide much needed in-patient care, she was also the only person present with public health training and experience. She knew what was needed.

In communicable disease control there is, in public health there is a pathway that needs to be followed and my skill and background, I have some understanding of that, of communicable disease and infection control.... you need to find out where the sources are. You need to deal with the sources. You need to collect information. You need to collect statistics. You need to be reporting to the ministry. There needs to be analysis. There needs to be care given the cases of the people with the illness. There needs to be teaching. There needs to be... environmental changes if necessary. So I could see that and I knew that that was an important role...

Nevertheless, she was acutely aware that she had not been assigned to the hospital to do public health work. She was a much needed in-patient nurse in a situation of scarce human resources and apparently in a context where local government was not able to step in.

And my dilemma is where is the best place for me to go? I had these acute care clients but yet there is a potential expansion of a disaster in another location. ... so my ethical dilemma was competing priorities. My colleagues did not have the skill sets that I had as a public health nurse. . . It was a feeling of being overwhelmed.... both roles are so important, both roles were needed. They were both needed now . . . It was both extremely urgent situations and knowing I had skills for both places. [It was] Feeling urgent, something urgent, a decision had to be made.... I was trying to think where is it best for me to be and I kept thinking it's best for me to be in both places, doing both jobs. (R12)

Rather than feeling empowered by her skills and knowledge, the respondent described 'I felt weak'. She struggled with not being sure where her skills were most needed, her feelings of responsibility for her patients, and the duty of care that she assumed towards those for whom she was currently responsible and the needs of the broader community and potentially outside this community.

\section{Case 3, Public Health and Vertical Programs}

As a public health practitioner and epidemiologist in Western Africa, another respondent was sent to tour rural villages in order to determine where meningitis outbreaks were emerging. This was part of a vertical program and the respondent describes that the project was not integrated with treatment for any other conditions besides meningitis.

The respondent reflects that an epidemiological approach also created patient-oriented ethical challenges, reflecting the participants' experience of a tension 
between community-oriented ethics and duties towards individuals (Atun et al., 2008; Devakumar, 2010).

So this is what's referred to as a vertical program and you know this is what public health officials struggle with. You can do a vertical program to attack something like polio or meningitis. You do it comprehensively and do a very good job but what you're missing is the horizon. Where, so I treat the one child in this clinic, lying on the floor with meningitis, the child beside that has a gangrenous foot, I'm going to leave them because they don't fall under my mandate. (R6)

The struggles for the practitioners seem to hinge on feeling uncertain about when they ought to accept and justify their actions on public health grounds and when they ought to resist the greater good justification, and attend to their duty of care for the patient. The respondents describe feeling torn, reluctance and moral distress at having to turn away people with legitimate needs because treating them might cause broader communitylevel harm.

\section{Discussion}

In the stories recounted by respondents in the qualitative study there was a frequent refrain of frustration at not being able to attend to the needs of a given patient for a variety of reasons. Usually the reason and justification for not attending to the needs of an individual rested on one of two rationales: either scarcity of resources or the greater good of a community. For example, where rationing decisions had to be made between patients such as premature infants in need of costly and scarce critical care, limited resources were claimed as the reason for choosing not to treat very premature babies because it was them against 'a child who has a chance' (Ref. C Blinded). In other cases, community interests were prioritized over individual interests where, e.g. treating for diseases like TB or HIV/AIDS could not be sustained because of security reasons and could lead to drug resistance. So tensions arose between one individual and another individual (sometimes an anticipated future individual), or between an individual and a community. In some ways, these cases look very similar to ethical challenges that arise in the home contexts of health practitioners. Stories of resource allocation are certainly not unique to any healthcare system. Nevertheless, the contextual features of the reports are different. As health professionals practicing in Canada, our participants had no experience of dealing with situations such as not treating someone for TB in case war broke out and treatment could not be continued. In addition they did not report being educated or coached to consider such dilemmas in ways that support an ethical decision process in such a situation. Their ethics training did not account for extreme circumstances such as war, massive population movements and extreme and pervasive poverty.

\section{The Clinical Ethics Model}

Traditional clinical ethics in the West is dominated, albeit not exclusively, by patient focused values (Pellegrino, 1999). By traditional clinical ethics, we mean the values and principles that inform the codes of practice of health care professions, as well as the prevailing models of bioethics which are promoted through education in Western health professional programmes including schools of medicine, nursing, therapy, etc. In the west, these tend to be informed by face-to-face interactions between health care professionals and patients and the ideal promoted is one of individual patient-oriented and even patient-directed care. Promotion of patient autonomy and/or patient's best interests are characteristic values of this model and have spawned further commitments to informed consent, the duty to protect confidentiality, shared decision making and comparable patient-oriented values and principles (Charles et al., 1997).

Codes of practice of the professions are similarly directed, e.g. the Canadian Medical Association Code of Ethics (2004) is divided into sets of responsibilities, and primary among the Fundamental Responsibilities of a physician is 'Consider first the well-being of the patient'. Others require the physician to respect human rights and patient decision-making through informed consent. Likewise, the International Code of Medical Ethics of the World Medical Association places respect for patient autonomy second after the physician's duty of independence and professional conduct.

A physician shall respect a competent patient's right to accept or refuse treatment. (WMA)

It is this somewhat reductionist version of traditional Western clinical ethics that we draw upon because it is the one expressed in codes expected by many aid agencies. Those health professionals who travel without the support of NGOs and other organizations have no other professional codes of ethics to draw upon (though they will of course draw on personal beliefs and religious or secular commitments). As well, even healthcareoriented humanitarian aid organizations that have 
established value statements commonly stipulate that professional ethics codes, learned in training, are what they expect practitioners to be able to draw upon in the field (personal correspondence). For example, the Volunteer Charter of MSF states: 'Members undertake to respect their professional code of ethics'. (MSF Charter)

In our empirical study, the health professionals interviewed had clinical training, but few had specialist public health training. Nevertheless, the stories we collected indicate that values of public health ethics, such as the ones drawn from Dawson and Verweij (2008) above, are often present in aid organizations' policies, programmes and procedures, like vertical programmes that focus on single disease interventions. ${ }^{5}$ Moreover, the contexts of scarcity and contagion mean that, very often, individual interests are not the focus of humanitarian health aid. Rather, these interests frequently need to be sacrificed to promote greater good. As a result, international humanitarian health care professionals report that the clash in values between patient-oriented clinical ethics and community-oriented public health ethics is a source of confusion, ethical challenge and moral distress. With this also comes uncertainty about best practices in field-based care that can contribute to, or prolong the suffering of patients, as well as compound factors that contribute to burn out of health care practitioners, so fewer are able to do this much needed work.

An important insight from the studies then, is the degree to which traditional teaching and values of professional health ethics seem insufficient for meeting the realities of health care practice during humanitarian missions. Patient-oriented values were not adequate for resolving various ethical challenges the respondents described. Instead, respondents spoke of 'the greater good' as the core guiding value or principle of the policies and programmes they were charged with enacting. At the same time, while none of the respondents used the term 'autonomy' in the narratives, they very often worried about and drew attention to instances of compromised patient autonomy such as situations where treatment proceeded without informed consent; and they agonized over the hindrances which they believed prevented them from adequately attending to individual patient suffering. Thus, ethical challenges emerged where greater good arguments rearranged clinical priorities and overwhelmed individual patient interests.

Whereas it offers important guidance in many cases, it also appears that traditional Western clinical ethics, which emphasizes individual patient needs and patient autonomy, is inadequate to guide responses to the inequities and other sources of ethical challenge described by humanitarian health professionals when applied in the contexts of scarcity and public health needs. Their training in health ethics for and from Canadian contexts is either insufficient guidance in the field, or even a source of the ethical conflict. For example, the ethics model the nurse in Case 1 is working with was, for her, inadequate to the situation. She felt a professional duty to attend to individual needs and clinical ethics training did not help her because it could only acknowledge that the situation was morally wrong and in many ways 'unbearable' (Tessman, 2010). Attending to the greater good was not, under the circumstances, a satisfactory alternative justification for withholding treatment from the dying child. The resulting moral distress can lead to burn out and diminished capacity of aid workers, and therefore of aid agencies (Wilkinson, 1987; Corley, 2002). It is also the canary in the coalmine as the stories of distress can highlight, especially for citizens of Western countries unfamiliar with the context, where there have been injustices and harm to patients in the global south.

\section{The Challenges Raised by Public Health Ethics Model}

What was striking in the qualitative data is the frequency with which the stories told invoked issues in public health ethics rather than traditional clinical health ethics, demonstrating that perhaps humanitarian health care workers are more directly exposed to the forces of community needs than certain clinical care providers are in their home contexts. Moreover, in the Canadian contexts, small specialized groups address population health needs; in humanitarian settings everyone seems to, regardless of their area of specialization, and the respondents indicated that humanitarian workers have to be mindful of the broader implications of their clinical decisions. As a result, it is a natural assumption that the ethical values of public health might be relevant to humanitarian health care provision. The reasons for this are linked to the contexts of scarcity, degree and likelihood of spread of infection, the extent of disease and the emphasis on health protection involved in humanitarian health care practice. These circumstances extend beyond the work of clinical patient care in the West and thereby confound the expectations of an ethics of clinical practice from the respondents' home settings.

In the United States, bioethics, as developed in the late 1960s and early 1970s, emphasized the 
central priority of individual autonomy, reflecting the individualism of American culture, in contrast to the social solidarity characteristic of many other cultures. (Gruskin and Dickens, 2006).

An emerging literature in public health ethics has helped to define and emphasize this community orientation to the exclusion of individual clinical encounters and health improvement (Mann, 1997; Benatar, 2006; Dawson and Verweij, 2008).

The authors cited describe how ethics in public health displaces the priority of individual interests and autonomy by focussing on protecting and enhancing community interests. This means that compromise and concession are required where individual needs are concerned. Respondents grappled with this, as one physician broadly characterized it,

You know public health is a wonderful thing but it is somewhat limited.... [Public health has] coloured international health for the last 50 odd years, 60 odd years, I suppose. And what it does is it diminishes the value of the individual... It diminishes the importance of illness and of treating illness. (R4)

These experiences are reflected in the impressions reported by local community members as well. In a detailed qualitative study led by Caroline Abu-Sada (2011) for MSF International, local patients', local health practitioners' and community leaders' perceptions were gathered about the work of MSF. While the impressions of MSF were generally excellent, there were still concerns about breadth of access in vertical programmes. 'When the general population is grateful for MSF's ability to tackle [a given disease, such as] Kalazar, people closer to the organization [e.g. local colleagues] tend not to agree with the limitations that are inherent to a vertical project'. For example, a local health professional from Kenya said,

They treat only one kind of disease [but there are other diseases that affect us badly] like malaria, typhoid, brucella, STD, meningitis and tuberculoses. (Abu-Sada, 2011)

Respondents in Abu-Sada's study pointed out that restrictions to responding to one type of disease meant that patients with other conditions could not receive care from aid organizations in situations where that meant therefore not receiving any professional medical care at all. This promoted confusion and risked generating distrust of the aid organization.

\section{The Burden of Responsibility}

Whether a public health ethics model or one of clinical ethics (or some third possibility?) is the right one for health professionals engaged in humanitarian health care, is an important question. Health professionals trained in patient-centred ethics find themselves confronted by situations in which applying this approach is thwarted, justifiably or not. They also find themselves at the coalface bearing the responsibility of having to refuse elements of care to real patients with significant, even lethal needs. Thus they are responsible for carrying out values of community health protection, patient-by-patient, forcing generals onto particulars.

Health professionals are not always properly prepared for this encounter with the tensions between individual and community interests. They are trained to focus on the intimacy of the needs of the patient before them and to let others take responsibility for wider interests (Schafer, 2001). They are expected to be advocates for their patients, and to be attentive to patient needs. In the context of humanitarian health care work, they become not just clinicians and advocates, but also gate-keepers and resource allocators; and while all health professionals play these roles to some extent, here denying resources to people in need became common-place and the consequences were disturbing because the alternatives available to patients were vanishingly few. Reflecting on such experiences, the respondents express feelings of culpability, regret and remorse (Dickenson, $2003)^{6}$, as if they had been compelled to act as judges of the worthiness of the people they went to help by turning people away from sometimes life saving resources. As one respondent put it, 'Oh yeah, you feel dirty in a way. I was this person who was judging people to be worthy or not worthy'. (R10)

In some cases, the respondent felt responsible for the decisions and outcomes for the people in the stories, whereas other times they saw themselves as relatively powerless to change or adapt how things unfolded. For example, in the cases listed above, respondents felt helpless and frustrated, but in some cases, they were quite clear that the best interests of the person before them could not be served without potentially creating greater harm to the community.

In theory at least, the degree of remorse a respondent felt was inversely proportionate to the degree of capacity they believed they had to change the circumstances, decision and outcome. Where decisions were made for them based on greater good-oriented public health values in laws and policies, the respondents describe regret but recognized they could not control 
the circumstances. Where they felt directly responsible for a clinical decision, the respondents describe feelings of remorse for the decisions and outcomes (even if control did not fully reside in their hands). In a very real way, the problem is that these are one and the same. Decisions based on greater good values are also individual patient decisions. They come together in specific patients. Unsurprisingly, it is in the public health-oriented stories that respondents were able to rely on 'greater good' or 'lesser harm' justifications for their actions that make them feel less responsible for regrettable outcomes.

The cases described from the stories reported by the respondents in our study suggest that while health is an uncontroversial shared value, it is not universally upheld as the most significant overarching value: some hold it instrumentally; others value it in and of itself (Radoilska, 2009). Our analysis revealed that there was a tension over whether to promote public health as an overriding goal, or whether there are other equally significant goals to promote, some of which may override wider health-related goods in favour of individual liberty, equity or other factors that challenge the public health orientation.

\section{Conclusions}

Humanitarian health care professionals exist at the point of contact between the laudable values of public health ethics and the palpable values of clinical ethics. In the cases described, the humanitarian health workers and, most importantly, their patients are inescapably located right where the tension between these two models becomes tragic reality. While the respondents recognize the importance of 'greater good' choices, there is suffering at having to assign (in the case of the health care providers) and worse, assume (in the case of the patients) the burdens greater good choices impose upon individuals. At this point, the distribution of burden feels obviously unfair. It does not resolve the unfairness to send a dying child home with nothing but food as a means of balancing the sacrifice. This runs contrary to the ethical training of clinicians who are told to 'consider first the well-being of the patient' (Canadian Medical Association, 2004). The inclusion of obligations to promote liberty, equity and reciprocity, etc. cannot resolve the tension altogether, but can go a long way towards ensuring that sacrifices are humanely attended to and burdens are more fairly distributed. Clinical ethics draws attention to this through its normative interest in the individual, so it is a sound balance for the general focus of public health. Even though neither is complete on its own for helping guide health professionals in the field, taken together these models have much to offer, so health professionals who provide humanitarian care ought to be trained in both public health ethics and clinical ethics. Nevertheless, the challenge remains: how do you adjudicate between them in particular circumstances when they conflict?

The question, 'what can be offered as even tentative response for how to adjudicate between the two models when faced with a particular issue?' has been raised here but not resolved. A critical insight from this study, at the level of the professional, is that both models are often directly salient in a given situation. And the consequences of valuing one model over the other are almost always born by the patient in devastating ways, and might well be equally significant for the community. We propose that a first step in ethical preparation for humanitarian health care practitioners is to help clinicians (and other relevant stakeholders) to recognize that both clinical ethics and public health ethics models may be present, and support them to think creatively about preserving both, like the nurse in Case 2 did. Where it seems they cannot both be preserved, prepare practitioners to ask why? Is it a lack of resources, or public health interests that are pressing for this decision? Or is this just how we've always done things?

Clinicians need to be prepared to address ethical challenges in humanitarian health care practice in ways that are relevant to the setting, using several layers of analysis to accommodate the questions described here. So even if the issues, values and principles turn out to be identical to other health care contexts, it would help for health care professionals to be prepared to order these elements according to priorities more relevant to the individuals and communities that are part of humanitarian work. This might incorporate the values of public health, clinical practice and possibly other elements (e.g. human rights) (Braveman \& Gruskin, 2003). Relevant ethical preparation could draw from existing theory and meta-theory in ethics, and potentially introduce new values and prioritizations. It would involve consideration of the macro issues related to global justice and economic distribution (Benatar, 2006). Ideally it would be a mutually developed approach to health ethics models that would include the needs and views of recipient communities, individuals and care providers at every level. 


\section{Acknowledgements}

We wish to express our appreciation to the respondents of this study and to the participants of the Points of Intersection Symposium who contributed helpful comments to this article.

\section{Funding}

Canadian Institutes of Health Research (grant no. EOG 84636). Private endowed chair award to L.S.; New investigator award from the Canadian Institutes of Health Research to C.S.

\section{Conflict of interest}

None declared.

\section{Notes}

1. The notion of model concepts is employed here because it is arguably the best way to illustrate that these two approaches to health practice are sufficiently distinct and contain the conceptual foundations for two different and sometimes opposed value bases. The foundations of each will be explored below in relation to cases from our study, and the values they invoke will be analysed for their applicability and merit in the context of humanitarian health care.

2. There are other models in health ethics, research ethics, e.g. which have relevance to humanitarian health care, and which promote greater good or individual orientations.

3. In other cases, a different but related problem emerged that queried the appropriateness of claiming a community/greater good justification at all.

4. This calls to mind Virginia Held's declaration that care precedes justice, in this case a normative expression of the statement that care ought not to be overwhelmed by detached justice claims for the greater good (Held, 2006: 17).

5. Though public health may not be the explicit intention behind the programmes. Thanks to Dr Philippe Calain for clarification on this point.

6. Here, we draw very loosely upon Dickenson's discussion of moral luck and degree of responsibility that can yield regret or remorse. Our cases are not discussed here as 'luck-' oriented, but because respondents felt varying levels of control and responsibility for situations, we assign similar categorizations. A high degree of feelings of responsibility are equated with remorse because the people felt they had the power to change something. Low levels of feelings of responsibility yield regret because the people felt the decision was out of their control-like luck.

\section{References}

Abu-Sada, C. and deSouza, M. Perceptions' Project Kenya Report, (5th July-8th August 2008).

Abu-Sada, C. (2011). Dans l'oeil des autres. Perception de l'action humanitaire et de MSF, s/d Caroline Abu-Sada, MSF, [In the Eyes of Others 40 years of humanitarian action: How do people perceive humanitarian aid?] Lausanne, Switzerland: Editions Antipodes.

Atun, R. A., Bennett, S. and Duran, A. (2008). Policy Brief: Health Systems and Policy Analysis. When do Vertical (Stand-alone) Programmes have a Place in Health Systems? World Health Organization available from: http://www.who.int/management/ district/services/WhenDoVerticalProgrammes PlaceHealthSystems.pdf [accessed 2 March 2012].

Benatar, S. (2006). Facing Ethical Challenges in Rolling Out Antiretroviral Treatment in Resource-poor Countries: Comment on "They call it "patient selection' in Khayelitsha”. Cambridge Quarterly of Healthcare Ethics, 15, 322-330.

Braveman, P. and Gruskin, S. (2003). Poverty, Equity, Human Rights and Health. Bullettin of the World Health Organization, 81, 539-545.

Canadian Medical Association. (2004). CMA: Code of Ethics. Available from: http://policybase.cma.ca/ dbtw-wpd/PolicyPDF/PD04-06.pdf [accessed 2 March 2012].

Charles, C., Gafni, A. and Whelan, T. (1997). Shared Decision-Making in the Medical Encounter: What Does it Mean? (or it Takes at Least Two to Tango). Social Science and Medicine, 44, 681-692.

Corley, M. (2002). Nurse Moral Distress: A Proposed Theory and Research Agenda. Nursing Ethics, 9, 636-650.

Dawson, A. and Verweij, M. (2008). Public Health Ethics: A Manifesto. Public Health Ethics, 1, 1-2.

Devakumar, D. (2008). Cholera and Nothing More. Public Health Ethics, 3, 53-54.

Dickenson, D. (2003). Risk and Luck in Medical Ethics. Cambridge, UK: Polity Press.

Gruskin, S. and Dickens, B. (2006). Human Rights and Ethics in Public Health. American Journal of Public Health, 96, 1903-1905. 
Held, V. (2006). The Ethics of Care: Personal, Political, and Global. Oxford: Oxford University Press.

Hilhorst, D. and Schmiemann, N. (2002). Humanitarian Principles and Organisational Culture: Everyday Practice in Médecins Sans Frontières-Holland. Development in Practice, 12, (3\&4).

Hunt, M. R. (2008). Ethics beyond borders : How health professionals experience ethics in humanitarian assistance and development work. Developing World Bioethics, 8, 2.

Hunt, M. R. (2009). Moral experience of Canadian health careprofessionals in humanitarian work. Prehospital and Disaster Medicine, 24, 518-524.

International Federation of the Red Cross and Red Crescent (IFRCRC). (1965). Seven Fundamental Principles, available from: http://www.ifrc.org/what/ values/principles/index.asp [accessed 2 March 2012].

Mann, J. (1997). Medicine and Public Health, Ethics and Human Rights. Hastings Centre Report, 27, 6-13.

Médecins Sans Frontières. Charter, available from: http://www.msf.ca/about-msf/msf-charter [accessed 2 March 2012].

Munthe, C., Sandman, L. and Cutas, D. (2011). Person Centred Care and Shared Decision Making: Implications for Ethics, Public Health and Research. Journal of Health Philosophy and Policy, doi: 10.1007/s10728-011-0183-y.

Pellegrino, E. (1999). The Origins and Evolution of Bioethics: Some Personal Reflections. Kennedy Institute of Ethics Journal, 9, 73-88.

Pictet, J. (1985). The Medical Profession and International Humanitarian Law. International Review of the Red Cross, 25, 191-209.

Radoilska, L. (2009). Public Health Ethics and Liberalism. Public Health Ethics, 2, 135-145.
Schafer, A. (2001). Bedside Rationing by Physicians: The Case Against. Healthcare Papers, 2, 45-52.

Schwartz, L., Sinding, C., Hunt, M., Elit, L., Redwood-Campbell, L., Adelson, N., Ranford, J. and De Laat, S. (2010). Ethics in humanitarian aid work: Learning from the narratives of humanitarian health workers. American Journal of Bioethics: Primary Research, 1, 45-54.

Sinding, C., Schwartz, L., Hunt, M., Elit, L., RedwoodCampbell, L. and Ranford, J. (2010). "Playing God because you have to": Canadian health professionals' narratives of rationing care in humanitarian and development work. Public Health Ethics, 3, 147-156.

Tessman, L. (2010). Idealizing Morality. Hypatia, 25, 797-824.

United Nations, Economic and Social Council. (1985). Siracusa Principles on the Limitation and Derogation Provisions in the International Covenant on Civil and Political Rights. U.N. Doc. E/CN.4/1985/4, Annex, available from: http://www1.umn.edu/humanrts/ instree/siracusaprinciples.html [accessed 2 March 2012].

WHO. (2007). Ethical Considerations in Developing a Public Health Response to Pandemic Influenza, prepared by Carl Coleman and Andreas Reis of the WHO Department of Ethics, Trade, Human Rights and Health Law, and Alice Croisier of the WHO Global Influenza Programme Unit in the Department of Epidemic and Pandemic Alert and Response.

Wilkinson, J. M. (1987). Moral Distress in Nursing Practice: Experience and Effect. Nursing Forum, 23, 16-29.

World Medical Association (WMA). Policies. Available from: http://www.wma.net/en/30publications/ 10policies/c8/index.html [accessed 2 March 2012]. 